\begin{tabular}{|l|lll|}
\hline & Journal : 11069 & Dispatch : 21-7-2007 & Pages : 13 \\
Article No. : 9156 & $\square$ LE & $\square$ TYPESET \\
MS Code : NHAZGD-3 & $\checkmark \mathrm{CP}$ & $\checkmark$ DISK \\
\hline
\end{tabular}

\title{
3 Flood hazard map of La Trinidad (NW Nicaragua). 4 Method and results
}

\author{
5 G. Furdada $\cdot$ L. E. Calderon $\cdot$ M. A. Marques
}

6 Received: 12 December 2005/ Accepted: 6 February 2007

7 (C) Springer Science+Business Media B.V. 2007

8 Abstract During the Mitch Hurricane event (October 1998), severe floods occurred in 9 the village of La Trinidad (Departamento de Estelí, NW Nicaragua), which spreads at the 10 margin of La Trinidad river. As a consequence, the need for hazard assessment and land 11 use planning to reduce the effects of these natural processes arose. Nicaragua is a developing country, which means that there is a scarcity of good quality data on which to base these hazard assessments (i.e., lack of detailed topographic maps, lack of meteorological and discharge data series). Therefore, the main objective of the present work was to generate a flood hazard map of La Trinidad by means of a simple method, with a resulting map easy to understand and to use by the municipality for land use planning. There is no topographic map of the area at a more detailed scale than 1:50,000. So the main document that supports all the data and on which the final hazard map was based is the orthophotograph at 1:5,000 scale (generated from vertical aerial photographs taken in 2000). The method used was based on classical interpretation of vertical aerial photographs (pre Mitch and a post Mitch event), detailed field work, inquiries among the population and analysis of the main pattern of storms occurring in the area. All these data allowed the reconstruction of different extensions and water levels corresponding to events of different frequency and magnitude, and the qualitatively association of them to three hazard levels by means of energy and frequency. The use of orthophotographs of 1:5,000 proved to be very useful both for the development of the work and for the presentation of the final map, because they are very easily understandable for people not trained in the interpretation of topographic maps.

Keywords Floods · Orthophotographs · Hazard maps · Land use planning ·

Nicaragua

G. Furdada $(\triangle) \cdot$ M. A. Marques

A2 RISKNAT Group, Dept. Geodinàmica i Geofísica, Facultat de Geologia, Universitat de Barcelona, c/ Martí i Franquès s/n, 08028 Barcelona, Spain

A4 e-mail: gloria.furdada@ub.edu 


\begin{tabular}{|l|lll|}
\hline & Journal : 11069 & Dispatch : 21-7-2007 & Pages : 13 \\
Article No. : 9156 & $\square$ LE & $\square$ TYPESET \\
MS Code : NHAZGD-3 & $\checkmark \mathrm{CP}$ & $\checkmark$ DISK \\
\hline
\end{tabular}

Nat Hazards

\section{Abbreviations}

32 AECI

International Cooperation Spanish Agency

33

AMUNIC

Association of Municipalities of Nicaragua

34 CIGEO

Center of Geoscientific Research (University of Nicaragua)

36 INDUROT

Swiss Cooperation Agency

37 INETER

Institute for N
Oviedo (Spain)

\section{ITGE}

39 MATE-

40 METL

41 PPR

42 SINAPRED

43 UB

44 USGS

Institute of Nicaragua for Territorial Studies

Spanish Geological Survey

Ministère de l'Aménagement du Territoire et de l'Environnement Ministère de l'Équipement, des Transports et du Logement

Plans de Prévention des Risques Naturels Prévisibles

National System for Disasters Prevention and Reduction

Universitat de Barcelona

United States Geological Survey

\section{Introduction}

During the Mitch Hurricane event (October 1998), severe floods, among other disasters, occurred in Central America. The village of La Trinidad (Departamento de Estelí, NW

50 Nicaragua), which spreads at the margin of La Trinidad river (Fig. 1), was one of the affected places. As a consequence of the damage caused by the flood, the need for hazard assessment and land use planning to reduce the effects of these natural processes arose.

La Trinidad basin is located in Las Cordilleras Centrales (Central Ranges), it presents slopes steeper than $30 \%$, and its altitude ranges from 500 to $1,400 \mathrm{~m}$ asl. The climate presents the features of tropical savannah, with precipitation ranging from $800 \mathrm{~mm}$ to $2,000 \mathrm{~mm}$ and temperatures ranging from $21^{\circ} \mathrm{C}$ to $25.5^{\circ} \mathrm{C}$. The basin land use consists of sparse forests, prairies, pastures and some crops. The main resources are subsistence

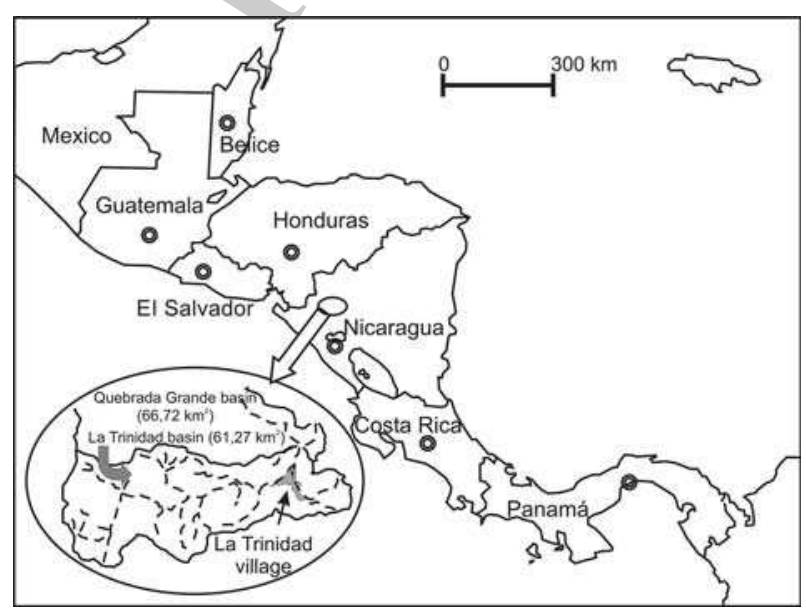

Fig. 1 Location of La Trinidad basin 


\begin{tabular}{|l|lll|}
\hline & Journal : 11069 & Dispatch : 21-7-2007 & Pages : 13 \\
Article No. : 9156 & $\square$ LE & $\square$ TYPESET \\
MS Code : NHAZGD-3 & $\checkmark \mathrm{CP}$ & $\checkmark$ DISK \\
\hline
\end{tabular}

Nat Hazards

agriculture and livestock. All the area is affected by severe deforestation. All these characteristics influence the runoff, favoring it.

Several climatic phenomena characterize the climate of all Central America and, in consequence, influence La Trinidad basin climate. These phenomena are the Inter Tropical Convergence Zone, the Easterly Waves, El Niño South Oscillation and La Niña (Fernández 2005). Also, the orographical effect forces the air masses to rise up due to La Cordillera Central relief. As a result, heavy rains take place associated with tropical storms every 2 or 3 years. According to the population, these rains produce discharges, which fill up the river bed without reaching the border of the lower terrace. Less often, more intense rainfalls with return periods of several years or a few tens of years produce medium magnitude floods.

As a consequence of climate and relief, natural disasters are usual in the area. Although Nicaragua is a developing country with scarce resources, there is some ongoing work focusing on natural hazards in this region. Related to La Trinidad area, in 1990 INETER presented the first national flood hazard map at a scale of 1:525,000, which showed that the region is prone to flood hazards. ITGE and INDUROT (2000) carried out the study "Peligrosidad por movimientos de ladera en Nicaragua. Cartografía piloto de la zona de La Trinidad" financed by AECI. This study focuses on slope instabilities and includes a map of La Trinidad basin at a scale of 1:50,000. COSUDE and AMUNIC (2002) presented the work "Análisis de riesgos y propuesta del Plan Municipal de Reducción de Desastres. Municipio de La Trinidad, Estelí". Landslide and flood prone areas were mapped at a scale of 1:50,000. Obviously, these works have a general prospective value. However, the level of accuracy needed in a flood hazard map cannot be achieved in a map at 1:50,000 scale, where $1 \mathrm{~mm}$ of map represents $50 \mathrm{~m}$ of real terrain, with contour lines equidistant to $20 \mathrm{~m}$ of elevation. At the very least, extensions of the floods should be mapped in detail to show the affected areas, especially in urban areas. The need of much more detailed cartographic basis is, therefore, obvious.

\subsection{Document constraints, lacks and limits}

Nicaragua, as other developing countries, is characterized by a scarcity of good quality data where hazard assessments can be based on. Some of the documents and data currently used to produce flood hazard maps do not exist in the area of La Trinidad. Topographic maps at a more detailed scale than 1:50,000 are not available. Rainfall series are scarce and discontinuous. There is no meteorological station in La Trinidad basin. There were five stations around the basin, but they were destroyed during the Mitch Hurricane event. Two of them provided data series shorter than 10 years. No data could be obtained from the other three stations. It is obvious that these data are not enough to calculate return periods of rainfalls and discharges accurately.

There is no gauging station in the basin. La Trinidad river is a tributary of Río Viejo river and the closest gauging station is La Lima, in Río Viejo. But the discharges in La Lima are affected by the Apanás dam exploitation. This dam is used to produce hydroelectric energy, and the water is spilled into the Río Viejo, upstream of La Lima gauging station. Obviously, the series of La Lima cannot be used to calculate discharge return periods.

The lack of detailed topographic or "digital" maps, meteorological and discharge series from gauging stations forced the need to look for other documents and data. As a consequence, the document used to produce the flood hazard map is the 1:5,000 orthophotographs because it is more detailed and up-to-date than available topographic maps. 


\begin{tabular}{|l|lll|}
\hline & Journal : 11069 & Dispatch : 21-7-2007 & Pages : 13 \\
Article No. : 9156 & $\square$ LE & $\square$ TYPESET \\
MS Code : NHAZGD-3 & $\checkmark \mathrm{CP}$ & $\checkmark$ DISK \\
\hline
\end{tabular}

Nat Hazards

The objective of this paper is to present a method adapted to the documents and data available in Nicaragua. This method will be applicable to other developing countries.

\section{Materials and methods}

107 The method used was based on classical interpretation of vertical aerial photographs (pre Mitch and a post Mitch event), detailed field work, inquiries among the population and analysis of the main pattern of storms occurring in the area, in order to determine the reference flood, the dynamics and the geomorphology of the flooded area.

As mentioned above, there is no point in using a topographic map at 1:50,000 scale as the basic document to produce a detailed flood hazard map. On the other hand, orthophotographs at 1:5,000 scale (generated from vertical aerial photographs taken in 2000) were available. Therefore, the method is based on the use of these detailed otrophotographs; these are the documents that support all the data and on which the final hazard map was based. They allow a perfect location of geomorphological indices and other flood related data, even though elevations are not reflected on them.

The method consists of data collection and their overlap and analysis on a geomorphological frame. In the following sections we present the method.

\subsection{Photo interpretation of aerial photographs (pre and post Mitch event)}

Two series of aerial vertical photographs were used: pre and post Mitch hurricane flood.

The first step on data collection consisted of classical photo interpretation of aerial photographs of pre Mitch series (year 1996 at an approximate scale of 1:40,000). It allows a general overview of the area and the identification of the main fluvial forms, such as the main channel, the fluvial terraces (especially the lower ones), alluvial fans, etc. These data were verified in the field and mapped on the detailed orthophotograph.

An outstanding contribution was the Open skies series photographs, taken by the USGS in 1998, just after the Mitch hurricane. These photographs were taken at an original scale of about 1:120,000. Nevertheless, the quality of the originals is so good that allows their enlargement up to scales of about 1:8,000 without any loss of resolution. These pictures allowed the distinguishing of the points where the rivers overflow, the main preferential circulation channels shaped during the Mitch hurricane flood and the main patterns of sedimentation derived from the flood. The importance of these data will be discussed in the following section.

\subsection{Reference flood}

136 It would be very good to count on detailed maps showing the flood maximum limits and 137 water levels known from references (documents, pictures and/or eye witnesses), as ex138 pressed by Temez (1997) in the Jornadas parlamentarias sobre prevención de riesgos 139 relacionados con el agua. He added that the advantage of these documents is that they are 140 based on real data and not on results of theoretical calculations. In the same line of 141 thinking, the reconstruction of large magnitude floods of the past is one of the basic steps in 142 the French PPR method of flood hazard mapping (Garry and Graszk 1999). This also helps 143 in understanding the conditions of flood generation at this specific place and in evaluating 


\begin{tabular}{|l|lll|}
\hline & Journal : 11069 & Dispatch : 21-7-2007 & Pages : 13 \\
Article No. : 9156 & $\square$ LE & $\square$ TYPESET \\
MS Code : NHAZGD-3 & $\checkmark \mathrm{CP}$ & $\checkmark$ DISK \\
\hline
\end{tabular}

Nat Hazards

144 the consequences and damages. This selected event was grave, its low frequency can be associated to an extraordinary or extreme flood and it can be taken as a reference.

In La Trinidad case, the Mitch hurricane event (1998) produced the most important floods remembered in the region. As an advantage, it is very recent, so the forms are still quite fresh and memories are still quite good, abundant, and precise. Therefore, the flood related to the Mitch event was easy to reconstruct through photo interpretation, field-work and inquiries, and thus it was taken as the reference event.

\subsection{Geomorphological "silent witnesses"}

The "silent witnesses" are all the forms, sediments and different kinds of traces that can be observed and recognized by an expert, and which can provide information about the river dynamics and the floods, like extensions, water levels and processes related to the flood. Some "silent witnesses" are related to the long-term dynamics of the river, like terraces or mass movements, which can interfere with the river or add solid material to the flow. Undermining is especially important.

The "silent witnesses" were obtained from the pre and post Mitch aerial photographs and from field-work, and they were mapped on the orthophotographs.

\subsection{Historical data and inquiries}

The historical data about floods try to identify and characterize the main historical floods and to estimate their frequency and magnitudes. These data are very useful when gauging stations do not exist and can effectively complement and calibrate other type of data or calculations. Obviously, they are very important for hazard evaluation. It is basic, then, to obtain the dates of the floods and the water heights and extensions. Unfortunately, in the area of La Trinidad, archives or libraries where floods are recorded do not exist. Neither administrations nor churches record these kinds of events systematically. The only sources of historical data are inquiries to the older members of the population. The inquiries were 169 made in a random sample of the population. People living along the river and the quebrada provided the most interesting reports.

\subsection{Anthropic interactions}

Anthropic structures, obstacles and modifications on the river bed must be taken into account. They can divert the water flow, narrow the river bed and produce a rise of water level, interrupt the flow, generate local increases of energy of the flow, etc. As a result, they can modify the flood prone areas. The elements to be mapped are anthropic deposits reducing the channel section, dikes, docks, bridges, artificial channels, water input points,

180 All the data collected were classified and mapped on the orthophotographs in order to 181 prepare the integrated geomorphological map. Thereafter, the main geomorphological gravel extractions, etc. Especial emphasis has to be placed on structural defenses which are not well designed or constructed. criteria are noted. 


\begin{tabular}{|l|lll|}
\hline & Journal : 11069 & Dispatch : 21-7-2007 & Pages : 13 \\
& Article No. : 9156 & $\square$ LE & $\square$ TYPESET \\
MS Code : NHAZGD-3 & $\checkmark$ CP & $\checkmark$ DISK \\
\hline
\end{tabular}

Nat Hazards

For short distances, fluvial terraces maintain a quite constant elevation above the main channel. For this reason, they can be used as a reference level for the floods, which can overflow and inundate them or not. Localized water levels and extensions provided by inquiries and impacts on tree trunks can be interpolated and extrapolated by using the terraces reference level. At this point, it is very important to validate the information provided by local witnesses. In our study, the reference event was so strong and recent that no conflicts arose. Areas with sediment accumulation after a flood, determined by photo interpretation and field work, show the pass of the flow over that level. Channels shaped during an energetic, large magnitude event show the preferential overflow and circulation reaches in the case of water level rising. Damage caused during floods (which reflect the flow energy), undermining, and anthropogenic obstacles that can divert or interrupt the flow, must also be considered. The last two data are also relevant because they show the possible modification of the channel and the flooding area.

The geographic overlap of all these data and the use of the above criteria allowed a detailed reconstruction of the geomorphological frame of the area, of the reference flood and the understanding of the particular dynamics of La Trinidad river. The result is the integrated geomorphological map (Fig. 6). This map is the basis of hazard interpretation because it is possible to delimit the zones according to the level, the energy and the frequency of the flood. One of the main values of this map is that it is objective, so far as possible, so it is not subject to change depending on different interpretations. Therefore, it is a map that can always be used as a basis for new interpretations or, in the future, to calibrate calculations made with more sophisticated techniques.

\subsection{Interpretation of the hazard level}

Hazard can be defined as the set of natural aspects of a phenomenon (not social) that contribute to the expected damage. It has two components tightly related: severity and probability of occurrence (Ayala-Carcedo 2002). The possibility that a phenomenon happens, with a certain degree of severity or intensity, during a definite period of time in a defined area, represents the recurrence and the geographic location of this event and allows the estimation of the hazard.

In hazard evaluation, flood models are usually used to determine the hazard parameters, such as water depth and flow velocity (Pappenberger et al. 2006). Current models range from simply intersecting a plane representing the water surface with a Digital Elevation Model for estimating the flooded area (Bates and De Roo 2000; Priestnall et al. 2000), to full solutions of the Navier-Stokes equations. Combined one- and two-dimensional hydrodinamic models are quite recent developments, aimed especially at modelling inundation areas (Dhondia and Stelling 2002), even though the coupling of one-dimensional hydrodynamic models with two-dimensional methods (GIS) has been published in recent years (Bechteler et al. 1994; Estrela and Quintas 1994; Bates et al. 2003). Nevertheless, confidence in the model outputs is in many cases established through calibration of the model on past flood events (Pappenberger et al. 2006). It is widely accepted that the estimates of flood hazard involve estimating the probability that a given event exceeds a certain given magnitude. This probability is subject to considerable uncertainty (Blazkova and Beven 2004; Cameron et al. 2000; Pappenberger et al. 2006). On the other hand, methods based on the qualitative flood plain geomorphological characterization also deal with flood hazard determination (Garry and Graszk 1999; Arnaud-Fassetta et al. 2005; Ballais et al. 2005). 


\begin{tabular}{|l|lll|}
\hline & Journal : 11069 & Dispatch : 21-7-2007 & Pages : 13 \\
Article No. : 9156 & $\square$ LE & $\square$ TYPESET \\
MS Code : NHAZGD-3 & $\checkmark \mathrm{CP}$ & $\checkmark$ DISK \\
\hline
\end{tabular}

Nat Hazards

In this study, the hazard evaluation is mostly based on the Garry and Graszk (1999) method. It proposes a definition of the reference hazard. The reference hazard corresponds to an event of a chosen return period, selected because society wants to protect itself against this particular magnitude phenomenon. In terms of flood hazards and land use planning, the selected flood is the maximum well-known event (or reference event). When the reference event has a return period shorter than 100 years, the 100-year return period flood is chosen instead. Then, the hazard levels are determined as a function of the reference flood physical parameters (velocities and water levels). These parameters can be translated in terms of damage and gravity effects on people. The hazard levels are classified as low, medium and high, with the aim of simplicity and understandability. In this French method, the threshold of $1 \mathrm{~m}$ of water submersion is assigned to the high hazard level.

In summary, with the Mitch reference event and all the data and criteria obtained in La Trinidad, it is possible to reconstruct three different water levels corresponding to different severity and frequency, and so to different magnitude floods. The integrated data allowed us to qualitatively associate these three categories of floods with different hazard levels.

\section{Results}

The results reflect the two main steps of the process of generating the hazard map: first, the Integrated Geomorphological map, where all the original data are compiled and, secondly, the interpreted Hazard map.

\subsection{Integrated geomorphological map}

The Integrated Geomorphological map, as said before, is a map where all the data is compiled (geomorphology, morphology "silent witnesses", the reference flood, results from inquiries, etc.). It includes all the real data based on real forms, processes, water levels and extensions of the previous floods.

Photo interpretation data of pre and post Mitch event aerial photographs were verified in the field and mapped on the detailed orthophotograph. This constitutes the geomorphological frame where all the other flood indices are overlapped. The interpretation of these pre Mitch photographs show, as one of the first results, that a great part of the village of La Trinidad is built on the lower terrace (2-3 $\mathrm{m}$ above the river bed and the main channel), so it is prone to flooding. The zones with sediment accumulation (Fig. 6) determined by post Mitch event photo interpretation and field work, are usually located on the lower terrace. This shows the pass of the flow over that level. Also, by using the lower terrace reference level, localized water levels and extensions provided by inquiries (Fig. 2) and impacts on tree trunks (Fig. 3) were interpolated and extrapolated. Therefore, the Mitch flood extension was reconstructed in detail.

Other "silent witnesses" together with the inquiry results allowed us to locate preferential circulation channels shaped during the Mitch event in the lower terrace. Most were modeled from crevasse splay points, usually related to high-energy flows at concave margins of meanders. Furthermore, when intermediate floods occur these channels are the main circulation reaches, since there is not enough water to cover the whole terrace. This type of dynamics was verified in the 2003 winter event. Should a flood similar to the Mitch occur, these channels will be sectors with high speed and depth, although they will be modified during the event. 


\begin{tabular}{|l|lll|}
\hline & Journal : 11069 & Dispatch : 21-7-2007 & Pages : 13 \\
& Article No. : 9156 & $\square$ LE & $\square$ TYPESET \\
MS Code : NHAZGD-3 & $\checkmark$ CP & $\checkmark$ DISK \\
\hline
\end{tabular}

Nat Hazards

Fig. 2 Woman showing the level reached by the water during the Mitch hurricane event (black discontinuous line). La Trinidad, 2004

Fig. 3 Impact marks on the trunk of a tree that grows on la Trinidad river bed. The impact marks were produced during the Mitch hurricane event. Black arrows indicate the higher impacts, produced by floating trunks. In the background, the level of the lower terrace is indicated with a black discontinuous line. La Trinidad, 2004
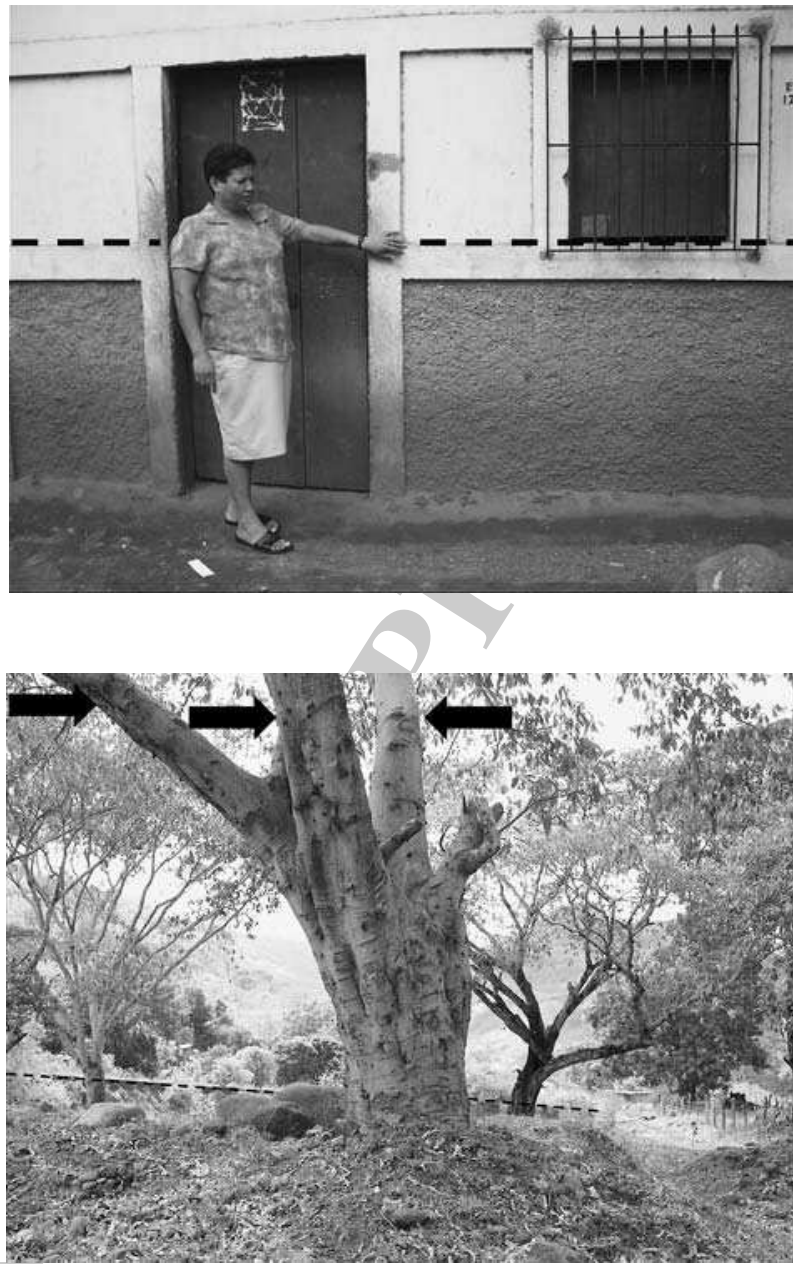

On the other hand, the heavy rains associated with tropical storms every 2 or 3 years produce discharges which fill up the river bed without reaching the border of the lower terrace. This particular dynamic could be reconstructed thanks to the inquiry information. These findings are discussed below and support the idea that traditional knowledge is characteristically local and held by people at risk (Handmer 2004). Therefore, it is important to record this kind of information and prevent it from being lost or not taken into 278 account.

Reaches affected by undermining (Fig. 4) were mapped. It shows, on one hand, some preferential overflow points, and on the other hand, unstable reaches and tendency of meander evolution. Consequently, undermining indicates possible changes in flood prone areas.

Damage produced during the Mitch event (which reflect the flow energy) and post Mitch anthropogenic obstacles were also mapped and considered. Figures 4 and 5 show an example of a too short dike in a meander undermining zone and of an anthropogenic deposit into the river bed. 


\begin{tabular}{|l|lll|}
\hline & Journal : 11069 & Dispatch : 21-7-2007 & Pages : 13 \\
& Article No. : 9156 & $\square$ LE & $\square$ TYPESET \\
& MS Code : NHAZGD-3 & $\vee$ CP & $\vee$ DISK \\
\hline
\end{tabular}

Nat Hazards

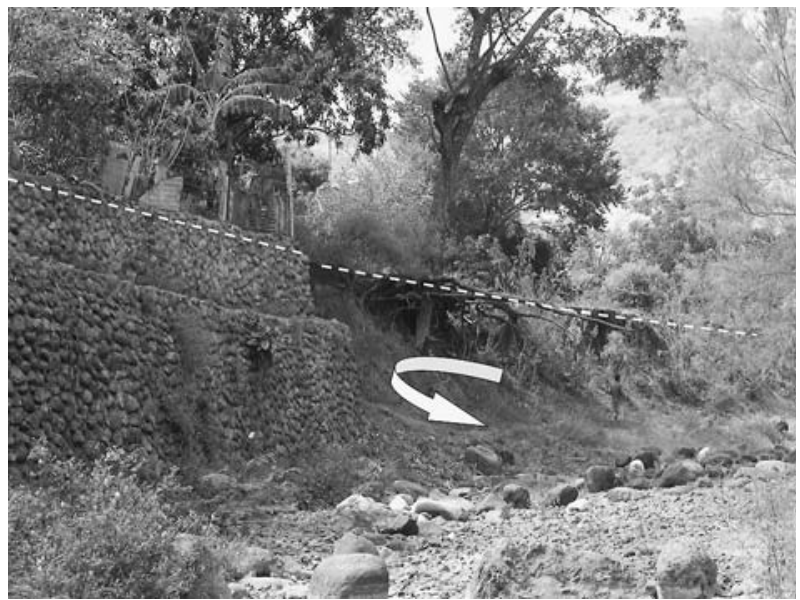

Fig. 4 Image of the concave margin of a meander. Undermining is evident below the roots of the tree, where unconsolidated sediment is being eroded (white arrow). The dike, built after the Mitch hurricane event, is obviously too short and undermining is beginning to act behind it and therefore it will be ripped off. The lower terrace level is indicated with a white discontinuous line. La Trinidad, 2004

An example of a conflict point is the stadium. Built on the Quebrada de la Chisgastosa bed, just upstream of the confluence with La Trinidad river, the stadium produces an obstruction to the flow. The water is then forced to flow between the stadium and the Panamericana road. The result is its rising up to higher levels than in natural conditions upstream and downstream. The consequences are more frequent floods, especially downstream of the stadium, that cover the lower terrace of La Trinidad and affect several houses.

An example of this map, made on the orthophotograph, is shown in Fig. 6. The legend of the map shows the main geomorphologic features (symbols 1-8), some relevant points where eyewitness information was provided and the reconstruction of the reference event (symbols 9 and 10) and the anthropogenic defenses and obstacles to the flows (symbols 11-14).

Fig. 5 Image of a filling on La Trinidad river bed indicated with a white circle. The dike, built after the Mitch hurricane event, presents a discontinuity and erosion is beginning to act behind it (white arrow). The lower terrace level is indicated with a white discontinuous line. La Trinidad, 2004

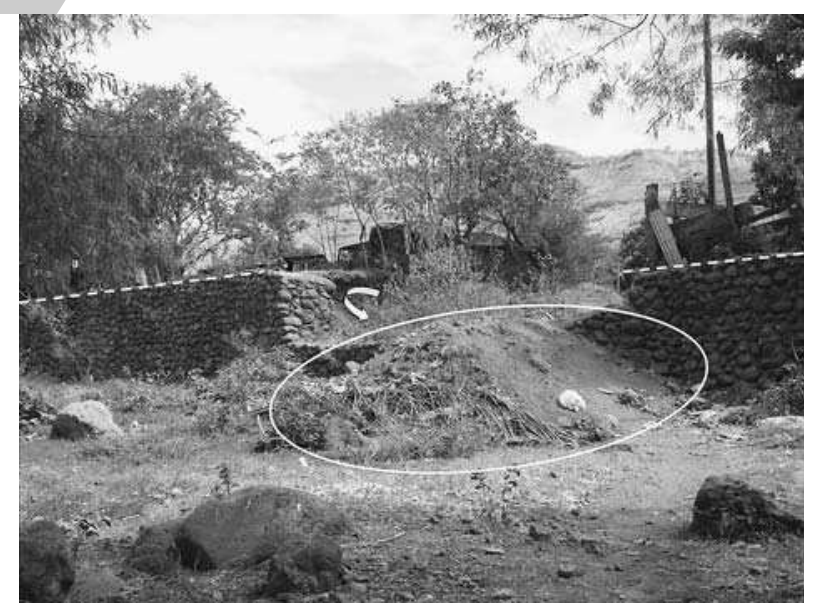




\begin{tabular}{|l|lll|}
\hline & Journal : 11069 & Dispatch : 21-7-2007 & Pages : 13 \\
& Article No. : 9156 & $\square$ LE & $\square$ TYPESET \\
MS Code : NHAZGD-3 & $\vee$ CP & $\checkmark$ DISK \\
\hline
\end{tabular}

Nat Hazards
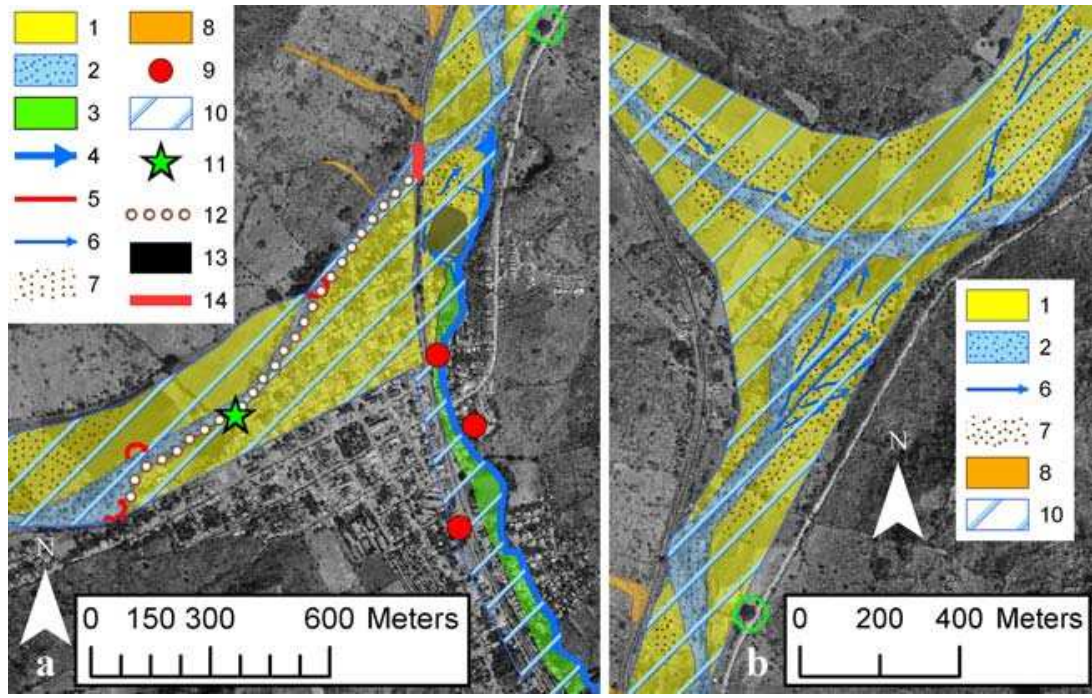

Fig. 6 Integrated Geomorphologic Map. (a, b) Two sectors of La Trinidad study area. The green circle indicates the same tree in the two sectors. 1 Lower terrace (2-3 m above the main channel); 2 river bed, including the main channel; 3 lower terrace of La Chingastosa stream $(\sim 0.5 \mathrm{~m}$ above the main channel); 4 La Chingastosa main channel; 5 undermining; 6 preferential overflow channels modeled during the Mitch event; 7 sediments deposited during the Mitch flood; 8 debris flows; 9 points with information from inquiries selected because their relevance; 10 reconstruction of the reference flood (Mitch event); 11 anthropic fillings; 12 dike; 13 stadium; 14 bridge

\subsection{Hazard map}

299

300

301

302

303

304

305

306

307

308

309

310

311

312

313

314

315

316

317

318

319

320

Derived from the geomorphological map, the flood Hazard map represents an interpretation of the different levels of hazard in the area (Fig. 7).

The first step according to the Garry and Graszk (1999) method is to define the reference hazard (see Interpretation of the hazard level). As said before, data on quantitative frequencies of flood discharges or of rains do not exist in this area.

The only significant information obtained was that, more or less 50 years ago, there was an important event. The river overflowed and flooded the lower terrace, where La Trinidad village now spreads. Anyway, this event generated less damage than the Mitch reference event. INETER (1998) lists the tropical storms King (October 1950) and Alice (May 1953). The Gilda hurricane (September 1954) did not affect Nicaragua. Both tropical storms happened about 50 years ago. Probably, these storms did not affect the whole territory of Nicaragua, just like the Mitch hurricane. The remembered event can correspond to any of both tropical storms. Even though its quantification is impossible, the existence of two flood events that affected the lower terrace of La Trinidad river gives a qualitative frequency of important, destructive floods.

In the $\mathrm{La}$ Trinidad case, the selected reference hazard corresponds to the Mitch flood (1998). This flood, at least, has a centenary return period: the Mitch hurricane is considered the third strongest hurricane occurred in the twentieth century in Central America; in Nicaragua, the rainfalls were closely related to the cloudy spiral bands of the hurricane. Rainfall frequency analysis gave as a result return periods of 500 years for dry areas and $>100$ years for the humid areas of Nicaragua (INETER 1998). Therefore, it is likely that floods related to these rainfalls had similar return periods. Furthermore, the Mitch flood is the worst ever 


\begin{tabular}{|l|lll|}
\hline & Journal : 11069 & Dispatch : 21-7-2007 & Pages : 13 \\
Article No. : 9156 & $\square$ LE & $\square$ TYPESET \\
MS Code : NHAZGD-3 & $\checkmark \mathrm{CP}$ & $\checkmark$ DISK \\
\hline
\end{tabular}

Nat Hazards

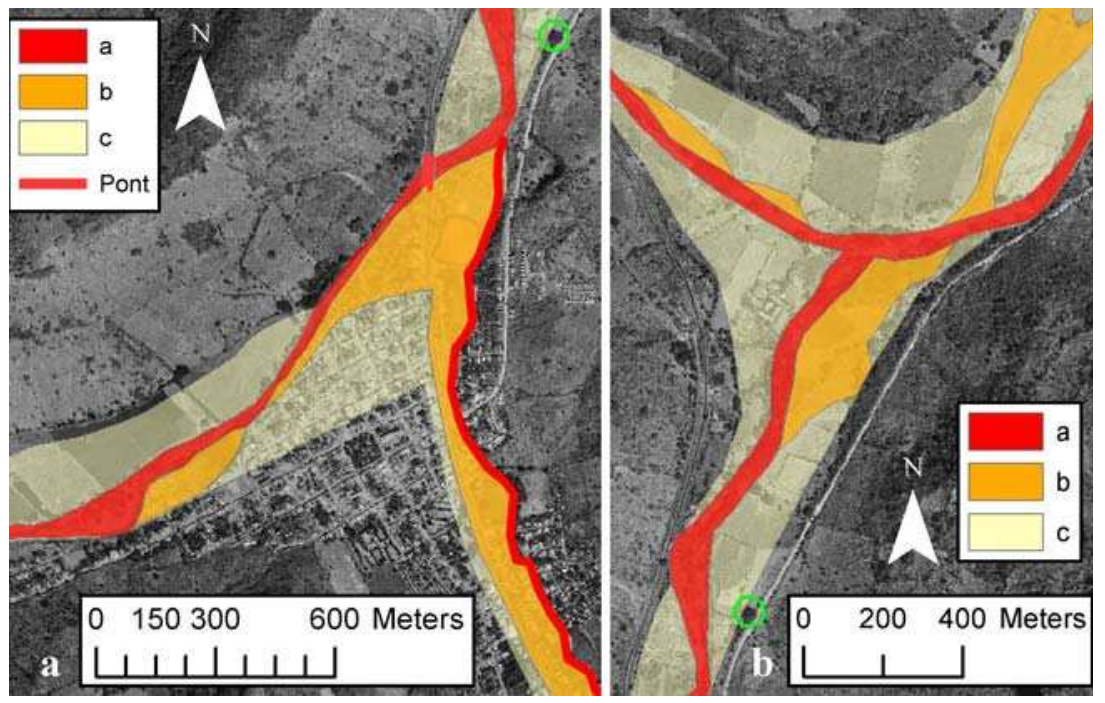

Fig. 7 Flood Hazard Map. (a, b) Two sectors of La Trinidad study area. The green circle indicates the same tree in the two sectors. $a$ High hazard level; $b$ medium hazard level; $c$ low hazard level

remembered in La Trinidad. The reconstruction of the Mitch reference event, including the morphology on the river bed and on the lower terrace remodeled during this event, and the anthropogenic interactions on them, was the basis for the interpretation of the hazard levels.

The Mitch flood was then used as a reference hazard level frame where the smaller magnitude floods were incorporated. Every 2 or 3 years there are discharges which fill up the river bed without reaching the border of the lower terrace. Less often, with return periods of several years or a few tens of years, there are medium magnitude floods. These floods fill up the ordinary channel and the river bed, and also overflow, but only circulate along the preferential channels modeled during the Mitch event, that is, do not affect the whole extension of the lower terrace. The main circulation channels during the small and medium magnitude floods correspond to the most energetic circulation zones during the reference event (highest water levels and flow velocities). Thus, logically, there is a coincidence between the most frequently flooded areas and the higher water levels. In contrast, the lower terrace is only completely flooded during low frequency, large magnitude events. All these facts allow the assignation of three different hazard levels to the different reaches and the lower terrace in the area.

These three hazard levels are represented with semitransparent red, orange and yellow colors for high, medium and low hazard, and presented on the orthophotograph. This presentation allows an easy interpretation of the areas subject to more severe or less severe floods and the level of hazard. It also allows an easy visualization of the vulnerable elements exposed, therefore constituting a good tool for municipal risk management.

\subsection{Conclusions}

The method is very well adapted to the constraints and characteristics of the developing countries and, in addition, it is simple, economic and efficient. The main contribution of the method is the use of detailed orthophotographs as the base of the work as well as the final product. 


\begin{tabular}{|l|lll|}
\hline & Journal : 11069 & Dispatch : 21-7-2007 & Pages : 13 \\
& Article No. : 9156 & $\square$ LE & $\square$ TYPESET \\
MS Code : NHAZGD-3 & $\checkmark$ CP & $\checkmark$ DISK \\
\hline
\end{tabular}

Nat Hazards

The use of orthophotographs proved very useful both for the development of the work and for the presentation of the final maps. The resulting products are more up-to-date, precise, efficient, and easy to understand than those that could be produced on the available 1:50,000 maps.

The first product of the work is the Integrated Geomorphological map, which compiles all the real data obtained. The great value of this map is that it is objective, as far aspossible, and it is not subject to change depending on different interpretations. Therefore, it is a map that can always be used as a basis for new interpretations or, in the future, to calibrate calculations made with more sophisticated techniques.

The detailed orthophotographs allowed a good representation of the extension of the reference flood. For this flood, different levels of energy corresponding to the flow along or covering different fluvial forms (i.e., channels and terraces) could be deduced in detail. All the data collected allowed the reconstruction of different water level heights, spatially related to the different channels. These channels, and therefore the related different water levels, correspond to different frequency and magnitude events and could be qualitatively associated to different hazard levels. For this reason, the velocity of the flow need not be specifically calculated.

Besides, the final Hazard map presented on the orthophotograph is very easily understandable for people not trained in the interpretation of topographic maps. Therefore, this helps the organization at the municipal level and also the self-organization of the community.

The limits of the hazard map are intrinsically related to the fluvial processes and dynamics. This means that channel changes due to sedimentation and erosion, often related to land use changes, can happen. Also, large floods can produce avulsions and changes of channel paths. This means that the map should be periodically revised and adapted in the future, when these changes occur, as with the entire existing flood hazard maps produced by any existing method.

Acknowledgements We want to thank the financial and logistic support of the following institutions: COSUDE, CIGEO and UB. We want also thank the following persons: Ing. Dionisio Rodriguez, Director of CIGEO; Ing. Marvin Valle (CIGEO), Director of the "Maestria Centroamericana en Evaluación de Riesgos y Reducción de Desastres"; Dr. J.M. Vilaplana, coordinator of the UB group in Nicaragua; Dr. J. Calvet (UB) for his comments and suggestions during field work; M. Guinau (UB) for her technical help; and Ing. Jean Carlos Gutierrez (CIGEO) for his technical and scientific support.

\section{References}

Arnaud-Fassetta G, Cossart E, Fort M (2005) Hydro-geomorphic hazards and impact of man-made structures during the catastrophic flood of June 2000 in the Upper Guil catchment (Queyras, Southern French Alps). Geomorphology 66:41-67

Ayala-Carcedo F (2002) Introducción al análisis y gestión de riesgos. In: Ayala-Carcedo F, Olcina J (coords.), Riesgos Naturales, Ariel Ciencia, Barcelona, Spain, pp 133-146

Ballais J, Garry G, Masson M (2005) Contribution de l'hydrogeomorphologie a l'evaluation du risque d'inondation : le cas du Midi mediterraneen francais. C R Geosci 337:1120-1130

Bates PD, De Roo APJ (2000) A simple raster based model for flood inundation simulation. J Hydrol 236:54-77

Bates PD, Marks KJ, Horrit MS (2003) Optimal use of high resolution topographic data in flood inundation models. Hydrol Prrocess 17:537-557

Bechteler W, Hartman S, Otto AJ (1994) Coupling 2D and 1D models and integration into Geographic Information Systems (GIS). In: White WR, Watts J (eds) Proc 2nd Int Conf on River Flood Hydraulics. Wiley, Chichester, UK, pp 155-165 


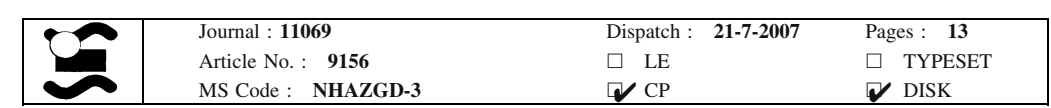

Nat Hazards

396

397

398

399

400

401

402

403

404

Blazkova S, Beven K (2004) Flood frequency estimation by continuous simulation of subcatchment rainfalls and discharges with the aim of improving dam safety assessment in a large basin in the Czech Republic. J Hydrol 292:153-172

Cameron D, Beven K, Tawn J (2000) Modelling extreme rainfalls using a modified random pulse BartlettLewis stochastic rainfall model (with uncertainty). Adv Water Resour 24(2):203-211

COSUDE and AMUNIC (2002) Análisis de Riesgos y Propuesta del Plan Municipal de Reducción de Desastres. Municipio de La Trinidad, Estelí. (unpublished)

Dhondia JF, Stelling GS (2002) Application of one-dimensional two-dimensional integrated hydraulic model for flood simulation and damage assessment. In: Falconer RA, Lin B, Harris EL, Wilson CAME (eds) Proc 5th International Conference in Hydroinformatics, Vol. 1, Cardiff UK, pp 265-276

Estrela T, Quintas L (1994) Use of GIS on the modelling of floods on floodplains. In: White WR, Watts J (eds) Proc 2nd Int. Conf on RiverFlood Hydraulics. Wiley, Chichester, UK, pp 177-189

Fernández C (2005) Caracterización de la inundabilidad por avenidas de tipo flash-flood en el municipio de Jucuarán (El Salvador, CA). Msc Thesis. Universitat de Barcelona, Barcelona (unpublished)

Handmer J (2004) Global flooding. In: Stoltman JP, Lidstone J, DeChano LM (eds) International Perspectives on Natural Disasters. Kluwer, Dordretch, The Netherlands, pp 87-106

INETER (1998) Las lluvias del siglo en Nicaragua, Managua, $159 \mathrm{p}$

ITGE and INDUROT (2000) Peligrosidad por movimientos de ladera en Nicaragua. Cartografía piloto de la zona de la Trinidad (Departamento de Estelí). Nicaragua (unpublished)

Garry G, Graszk E (1999) Plans de prévention des risques naturels (PPR) : risques d'inondation, Guide méthodologique. Ministère de l'Aménagement du Territoire et de l'Environnement, Ministère de l'Équipement, Documentation Française, Paris, p 123

Pappenberger F, Matgen P, Beven KJ, Henry J, Pfister L, Fraipont de P (2006) Influence of uncertain boundary conditions and model structure on flood inundation predictions. Adv Water Resour 29:14301449

Priestnall G, Jaafar J, Duncan A (2000) Extracting urban features from LiDAR- derived digital surface models. Comput Environ Urban Syst 24:65-78

TEMEZ JR (1997) Jornadas parlamentarias sobre prevención de riesgos relacionados con el agua. Sesión VI . La protección civíl ante el riesgo de inundaciones. Madrid, Senado 24 y 25 de noviembre 1997 (ejemp. policopiado) 